\title{
The Impacts of Mobile-Assisted Language Learning (MALL) on Freshmen's Vocabulary Acquisition and Their Perspectives
}

\author{
Thang Nguyen Van ${ }^{1 *}$, Ha Nguyen Thi Thanh ${ }^{2 *}$ \\ ${ }^{1}$ Thanh Dong University (TDU). \\ ${ }^{2}$ University of Economics - Technology for Industries (UNETI) \\ *Corresponding authors.Email: nguyenvanthang305@gmail.com,nttha.khoann@uneti.edu.vn
}

\begin{abstract}
This action research aims to explore the impacts of Mobile-Assisted Language Learning (MALL) on freshmen's vocabulary acquisition as well as their perspectives towards this learning approach. Twenty-six students at Thanh Dong University, Hai Duong province, Vietnam, participated in the eight-week intervention in semester 2, the academic year 2020 - 2021. The researchers employed pre-test, post-test as well as delayed post-test, attitudinal questionnaire and semi-structured interview to triangulate the collected data. T-test and Cronbach's alpha coefficient were calculated via SPSS 25 to determine the validity and internal consistency reliability of the research. The findings indicated that the MALL-integrated classrooms not only provided a significantly enriched vocabulary achievement among participants but also promoted their motivation towards the use of MALL to enhance their lexical knowledge. Some pedagogical implications have been additionally recommended for educators in teaching vocabulary and in future research on the development of a MALL-enhanced framework for vocabulary acquisition.
\end{abstract}

Keywords: Mobile-assisted Language Learning, MALL, vocabulary acquisition, perspectives.

\section{INTRODUCTION}

Over a decade has passed since the introduction of smartphones, and researchers have been looking at the use of cellphones in the classroom and for learning purposes; ever then, researchers discovered that both instructors and students think cellphones are a useful learning tool. Thus, they conducted in-depth investigations into how smartphones might be used to improve education in the classroom ([20](Kukulska-Hulme, 2009). A positive response has been obtained by the production of vocabulary apps and the combination of such applications on Android or iOS smartphones resulting in the development of many programs for installation on Android smartphones as well as iOS smartphones. Mobile devices make it easy to acquire knowledge while on the move for the majority of educational activities, including foreign language acquisition. Among the merits of mobile devices in language learning, according to [28] Nguyen (2016), are the ability for learners to become more engaged in learning materials and to choose activities that are most suited to their individual needs. By expanding the number of individuals who use mobile devices for language learning, it is probable that new environments for language learning will develop. As a result, further study on MALL should be conducted to enhance the teaching and learning process. While conducting the study, the researchers would like to get insight into not only the impacts of MALL but also the attitudes of students about it when they utilize mobile devices to learn English at Thanh Dong University (TDU).

It is possible to draw conclusions about the implications of moving transportation tools for language teaching and learning in order to aid mobile devices to enhance language teaching and learning. In addition, the study aims to contribute to the growth of knowledge on the MALL approach in the scientific literature. 


\section{LITERATURE REVIEW}

\subsection{Vocabulary in foreign language teaching and learning}

\subsubsection{Vocabulary}

The terminology "vocabulary" has many meanings based on its features, functions, and situations. [35] Soltani (2011) claims vocabulary is the essential factor connecting the four language skills in EFL. Having a good vocabulary helps you to understand what you hear, read, and write. [4] Brown (2000) defines vocabulary as a list or collection of terms that a language's speakers may employ. [3] Benettayeb (2010) defines vocabulary as the total number of words in a language. The learner would be unable to use and understand the target language without it. [22] Lewis (1993) asserts that "lexis is the heart of language" (p. 89). [33] Schmitt (2020) agrees that lexical items play such a crucial role when learners communicate that no messages are definitely produced or delivered without grammar or linguistics. Also, vocabulary is indicated as language's words, both singular and plural. The vocabulary definition seems to be more thorough and updated for this research.

According to [11] Day and Bamford (2005), vocabulary is an aspect connecting language abilities in EFL that learners are required to successfully listen, speak, read, and write. A lexical unit is a set of words that are used together to form a sentence. Researchers have created an outline of vocabulary concepts using the following definitions. Thus, instructors must help children discover and develop a lexical foundation with the aim to succeed in language acquisition and reading in particular.

\subsubsection{Vocabulary's functional role in foreign language teaching and learning}

Vocabulary is the smallest unit of a language. Communication is impossible without words. "Without grammar, very little can be conveyed," writes [41] Wilkins (1972, p.l1). This implies the importance of vocabulary. With just a few words in their head, individuals cannot express themselves or comprehend printed materials. Linguistic development requires vocabulary learning. To comprehend the target language's written and spoken forms, learners must have specific vocabulary knowledge. Lack of knowledge of the target language's lexis prevents second language learners from understanding and communicating in it. Students with big vocabularies comprehend under layered concepts at a faster speed than ones with little vocabularies ([18] Khachai, 2016).
The lowest unit of every language, according to [30] Pigada and Schmitt (2006), is the vocabulary. Thus, vocabulary is essential and plays a crucial function. The ability to communicate successfully with others depends on excellent vocabulary. To produce English in both spoken and written performance, learners must acquire a particular vocabulary. Vocabulary is the most important component of EFL since it connects the four skills.

\subsubsection{Incidental and intentional vocabulary learning}

[25] Meara (1994) claims two methods of vocabulary acquisition regarding incidental and intentional learning. While instructors guide students in purposeful learning, accidental learning happens without their knowledge.

Linguists define incidental vocabulary acquisition. Incidental vocabulary acquisition is described as an essential technique in vocabulary learning ([27] Nation, 1983). Reading, for example, may increase vocabulary knowledge unconsciously. [25] Meara (1994) categorizes vocabulary acquisition. Intentional or conscious learning is distinguished from accidental learning. Incidental learning, he says. In his view, accidental learning is not like purposeful learning, which is planned by instructors or students. That is, as students engage in activities like reading, speaking, doing, and engaging with others, they learn vocabulary. Incidental learning is described as learning something without trying to do so ([31] Richards \& Lockhart, 1994). It may also be described as a technique of learning either receptive or productive language skills to language usage while focusing on sections or texts. This approach involves considerable reading, listening to tales, viewing English movies, or participating in discussion outside or within classes, according to [30] Pigada and Schmitt (2006).

Intentional vocabulary acquisition is a popular and conventional technique of teaching vocabulary. [21] Kweon \& Kim (2008) term it the planned approach, which uses activities to extract forms chosen by instructors. It takes too long and is too difficult for learners to acquire language this way. Furthermore, purposeful vocabulary education involves bringing students' attention directly to the form and meaning of words via then, they use dictionaries or are provided with vocabulary lists, or even get teachers' explanations instantly. Intentional learning is fast and favored; yet, it has drawbacks. Many students encounter language in isolation and are unable to use it properly in context. [15] Joseph (2011) cited student mistakes. As an example, they confused "live" and "stay" with "we lived in a hotel for a week" since they only studied forms and their 
Chinese counterparts, not collocation and connection between words. Hence, they misused language. This shows students depend on memory and ignore semantics.

\subsection{Mobile-assisted language learning (MALL)}

\subsubsection{Key concepts}

Terminologies for mobile-assisted language learning (MALL) are always evolving. A lot of people disagree on what "mobility" means. For certain ideas in mobile learning, scholars have been looking for a complete, universal, and satisfying description.

The word "mobility" connotes a lot of different things. On the other hand, according to [20] Kukulska-Hulme (2009), the phrase "mobile learning" has two distinct meanings. For example, "mobile technologies" are portable and available at any time. It is also possible to define "mobility" as "mobility of the learner," i.e., the learner accessing knowledge from various locations and times. To define mobility, [16] Kakihara and Srensen (2001) stress the significance of both geographical and temporal mobility. In this view, [38] Traxler's (2007) viewpoint of mobile learning as several pedagogical services where portable devices are dominating technology is incomplete since it does not relate to student mobility. In addition, few authors, namely [38] Traxler (2007), [20] Kukulska-Hulme (2009) and [32] Samuels (2003), advocate the occurrences of MALL is when no fixed location is ensured during the learning process.

Mobile learning is a rapidly evolving area with many devices and apps. Mobile learning devices include basic single-purpose devices like music players, as well as multi-purpose high-tech gadgets like mobile phones and personal digital assistants, according to [39] Trinder (2005). This author suggests using mobile devices such as phones and GPS devices, and laptop computers to store and play MP3s or MP4s. Despite efforts to utilize these devices in artificial learning environments for experimental reasons, MALL has rapidly been taken many advantages when being used as excellent language learning materials.

An analysis in a recent [14] International Telecommunication Union (ITU) (2009) study pointed out that cellphones are the most commonly possessed and utilized mobile learning instruments, with about 4.6 billion subscribers worldwide. This number has been rapidly rising due to advances in the rapid growth of the mobile market. Mobile phones are used globally due to a few reasons. First, even the simplest phones include SMS (Short Message Service) functions, alarm clocks, and calendars to remind us of key events. Their MMS (Multimedia Message Service) capabilities let users send messages with images, audio, and text ([8] Collins, 2005). Mobile phones also provide basic personal information management features like address books and calendars, allowing users to ditch their phonebooks and agendas ([39] Trinder, 2005). The more appliances are integrated into cellphones, the more complex they become and function as a computer with a wireless system, navigation capabilities (GPS) or entertaining software. Consumers seldom see the potentiality of mobile phones as a learning tool ([29] Pettit \& KukulskaHulme, 2007), and only a few utilize them for learning reasons.

The widespread of mobile phones has spurred many creative academics and educators in recent decades. Several research has examined the usage of mobile phones and their fundamental functionalities in language acquisition. [19] Kiernan and Aizawa (2004) conducted one of the first research on mobile phone usage in education. Their research coupled MALL with task-based learning and highlighted many potential benefits of mobile phones in language acquisition. A number of studies ([37] Thornton \& Houser, 2005; [5] Cavus \& Ibrahim, 2007; [36] Stockwell, 2007; [17] Kennedy \& Levy, 2008) have focused on vocabulary acquisition through SMS and MMS, consequently leading to the assumption of those significant vocabulary learning tools. As shown in [37] Thornton and Houser (2005), students with MALL lessons could achieve new words more successfully than ones in a traditional classroom. According to [24] Lu (2008), the cellphone is a more effective lexical learning aid than conventional methods. But he emphasizes the value of involvement in the learning process. The same research found that students who read vocabulary messages often performed better on post-tests than students who viewed vocabulary messages seldom. In recent research, [7] Chinnery (2006) utilized mobile phones to access the Internet for educational reasons. They found that students were encouraged and stimulated to learn on WAP sites and had favorable views about utilizing those high-tech devices for MALL.

According to the aforementioned researches, mobile phones are used for education due to their access, low expenses, convenience and practicality.

\subsubsection{MALL as a vocabulary teaching approach in the language classroom}

\subsubsection{Benefits}

MALL devices and apps have been extensively studied since their introduction as an extension of e-Learning in the early 2000s. Most of 
these research either supported or disclaimed MALL as a teaching tool.

The portability of MALL devices has been highlighted in studies ([6] Cherian \& Williams, 2008; [7] Chinnery, 2006; [17] Kennedy \& Levy, 2008; [20] Kukulska-Hulme, 2009). This kind of learning is also not limited to four-wall classrooms. This unique characteristic of mobile devices has numerous benefits. Because MALL apps are portable, [17] Kennedy and Levy (2008), indicate that learners find them motivating. "The messages pushed me to go over topics or terminology covered in class beyond my normal study time," one of the students stated. (p.323)

Mobile phones, wireless laptops, and media players are among the most widely owned MALL devices ([14] ITU, 2009; [37] Thornton \& Houser, 2005). The "ubiquity" of MALL devices is defined by the principles of portability and broad ownership ([20] Kukulska-Hulme, 2009).

To better understand the benefits of utilizing MALL as a supplement, it is helpful to look at the benefits of using various MALL devices individually. For starters, mobile phones liberate students from location and time constraints, which is extremely encouraging. Students are more motivated to study when they may choose when and where they learn. Smartphones allow students to connect to the internet and access information at any time and place. [26] Nah, White, and Sussex (2008) showed that WAP sites were beneficial for EFL listening skills improvement and functioned as excellent supplemental learning methods to be utilized frequently outside the classroom. Other benefits of utilizing mobile phones as additional MALL devices include their low cost, large bandwidth ([14] ITU, 2009) of GSM servers and integration of many sophisticated capabilities in one device.

\subsubsection{Challenges}

Despite its many benefits, MALL may be harmful to both instructors and students. Studies performed thus far have shown both good and negative results, indicating that MALL is not as successful as previously believed. The challenges of utilizing MALL in education have also been noted ([17] Chinnery, 2006; [20] Kukulska-Hulme (2009); [38] Traxler, 2007).

One of the most used MALL devices, mobile phones, have been criticized for their small screens and one-finger data input ([17] Chinnery, 2006). These characteristics make mobile devices unsuitable for developing writing abilities. They also say that mobile phones are not appropriate devices for learning new material but may be used for reviewing and practice. From PC email users to mobile email users to face-to-face speaking learners, [19] Kiernan and Aizawa (2004) compared students' foreign language accomplishments across three categories. The students in the "mobile phone e-mail user group" were unable to finish the narrative assignments on time, while all the other students were successful. This inability to finish the narrative assignments on time may be due to one-finger data input and may indicate that MALL does not always improve all abilities in foreign language acquisition. Users' outcomes are increasingly recognized with visual products rather than verbal communication, which results in a failure in oral interaction.

\subsubsection{Attitudes of students and teachers towards implementing MALL in vocabulary acquisition}

\subsubsection{Theoretical framework}

The literature provides many definitions of attitudes, each depending on the research's viewpoint on attitudes. [42] Wise (1985) and [1] [2] Auzmendi (1991; 1992) studied attitudes from an emotional and cognitive perspective. Affective and behavioral components were later added by [40] Van den Berg et al. (2006). The Affective - Behaviroal - Cognitive model of attitude is one of the most recognized models of attitudes. The primary framework for MALL attitude still has three components: cognitive, affective, and behavioral. The first component Cognitive, deals with students' views of both the usefulness and simplicity of the use of mobile devices to learn English. It focuses on students' pleasure, enthusiasm, and fear while utilizing mobile devices to study. Behavioral offers information on the students' future decisions regarding employing mobile devices to study, whether or not they require assistance. Besides, the affective component indicates students' feelings and emotions towards using mobile in English learning.

\subsubsection{Attitude towards MALL}

Most academics believe that the majority of study on vocabulary acquisition through mobile devices focuses on effectiveness and attitude, typically via sending SMS to students ([43] Yang, 2012). [37] Thornton \& Houser's (2005) research is an early example. The authors compared the efficacy of vocabulary acquisition through email, mobile phones, and paper. Three times a day for two weeks, students were given vocabulary lessons. Five target words each week were defined, used in a variety of situations, reviewed, and incorporated into narrative episodes. In the first experiment, students were split into two groups of 13. They looked at two texts. Each set taught 10 words over 2 weeks. The first group received the messaging three times daily through 
email, whereas the second was strongly advised to study the identical material on a mobile website. Students who got lessons through email on their phones acquired more vocabulary than those who received lessons online, by $75 \%$ and $35 \%$, respectively. A second experiment split students into two groups. This time, 43 individuals learned the language on paper, while 25 others learned it through email delivered via mobile phones. The group taught through email outperformed the group taught via paper and pen in this second trial, confirming Thornton \& Houser's initial experiment ([37] Thornton \& Houser 2005). The Paper group averaged 3.8 while the Mail group averaged 6.4. The two studies performed by [37] Thornton \& Houser (2005) showed that students acquired more vocabulary when taught through email. The students' views about using a website that included explanations, quizzes, and videos about English idioms were also examined. This website was rated by 31 students who stated their preference of using the website and judging on their scores.

[24] Lu (2008) examined the efficacy of vocabulary acquisition through mobile phones with Taiwanese EFL students. The research included 30 people. Their English proficiency was moderate. The participants were split into two groups, a control and an experimental group, based on their class ranks in the S-shape distribution. Her study included providing one group vocabulary lessons through SMS and the other using print materials. After two weeks of testing, both groups had improved from pre-test to post-test. The experimental group outperformed the control group in the delayed posttest, although the trend remained the same. For the delayed posttest, none of the improvements were statistically significant. To acquire vocabulary through mobile phones, [24] Lu (2008) interviewed learners. They were asked to rank affirmations from 1 to 5 on a scale. Overall, participants considered the mobile approach appealing and handy. They also felt that mobile phones helped them acquire language. They said they liked learning through mobile phones and wanted to keep doing so.

[28] Nguyen (2016) conducted a survey on student preparedness in the context of language instruction in Vietnam. The findings show that most participants had cellphones and that $67 \%$ of them utilized them to study a language. The poll findings indicate that students like MALL. $35 \%$ of participants thought the courses were extremely efficient, and $45 \%$ said they were efficient with mobile learning. [28] Nguyen (2016) concluded from his survey that mobile learning might be used to teach and learn the Vietnamese language. [12] Do (2020) studied participants' views towards MALL.
The study's objectives were accomplished using a mixed-method research design using a survey questionnaire as the primary data collecting instrument. Both qualitative and quantitative statistics show that participants had favorable views about MALL in the classroom and MALL in general. English language education and learning should embrace MALL as a new method.

The majority of the empirical overseas and domestic researches cited above demonstrate the use of mobile technology for language learning. Most of the studies employed the experimental design, mixedmethod design or survey design. In the Vietnam teaching context, there has been a shortage of research articles investigating the application of MALL in classroom settings, especially utilizing action research design. Therefore, the authors decided to conduct a project serving the aims of exploring the effects of MALL on vocabulary development and students' perspectives towards this technologyassisted teaching in the way of action research.

\section{RESEARCH METHODOLOGY}

\subsection{Research design}

[9] Cresswell (2014) delves into the fundamental characteristics of action research. To begin with, researchers undertake action research to examine practical problems and attempt to resolve an urgent, real-world problem. Moreover, action research enables educators to get a greater understanding of and improvement in their educational methods. Another feature of action research is that it entails the involvement of many people and organizations, with responsibilities that may change and be negotiated. In addition, action research is a "spiral of actions" that includes constant reflection on the issue, data gathering, and action. Finally, an action research's outcome may be readily communicated and implemented instantly among teachers, school staff, parent organizations, and other stakeholders.

After weighing the aforementioned features, the researchers chose action research as the research method for this study in order to evaluate their own practices in teaching and learning vocabulary and to identify suitable techniques to enhance their students' vocabulary knowledge.

\subsection{Research questions}

This study aims to explore the influences of MALL on students' vocabulary acquisition and their perceptions towards this technology-based teaching approach at TDU. Therefore, the researchers 
conducted an action research project to address two questions:

- To what extend does MALL influence the students' vocabulary acquisition at TDU?

- What are the students' perspectives towards the application of MALL at TDU?

\subsection{Setting and participants}

The research included twenty-six first-year students from 1A11-QTKD and 1A11-CNTT at Thanh Dong University, Hai Duong province, Vietnam. Prior to starting the MALL study, the teacher-researchers solicited volunteers from students in the class. The teacher-researchers made it very apparent to them that participating in this study or not would have no effect on their class grades, and all twenty-six students were eager to participate. The class is comprised of 26 students from the Departments of Business Administration and Information Technology. Table 1 shows details about participants' age and gender distribution.

The participants consisted of $73.08 \%$ females and $25.92 \%$ males with an average age of 20.0 years old. They hail from several regions in Northern Vietnam. Some of them spent seven years in high school learning English. Some have learned in as little as three years. As a result, their English proficiency was varied. However, they had only completed the first term at the time of the research, and their English proficiency was expected to be the relatively elementary level of proficiency.

Table 1. Participants' age and gender distribution

\begin{tabular}{|l|c|c|c|c|c|c|}
\hline \multirow{2}{*}{} & \multicolumn{3}{|c|}{ Aged 18-20 } & \multicolumn{3}{c|}{ Aged 21-22 } \\
\cline { 2 - 7 } & Female & Male & Subtotal & Female & Male & Subtotal \\
\hline Total $(\mathrm{n})$ & 9 & 5 & 14 & 10 & 2 & 12 \\
\hline Total $(\%)$ & 34.62 & 19.23 & 53.85 & 38.46 & 6.69 & 46.15 \\
\hline
\end{tabular}

\subsection{Data collection instruments and analysis}

\subsubsection{Pre-test, immediate post-test and delayed post-test}

Pre-test, immediate post-test and delayed post-test was used to assess the impact of MALL on freshmen's vocabulary acquisition. In order to prevent students from using memory methods to recall words, the same test content with different order was performed without their knowledge. The quantitative data gathered from those tests was to assess the treatment's impact. To ensure the test's dependability, students were also told that the findings would not influence their grades.

The vocabulary test was assessed using [13] Horst's (2005) vocabulary self-report checklist. The test consisted of 150 words, with three options: YES (I know what this word means), NS (not sure - I have an idea what this word means, but I am not sure) and NO (I do not know what this term means). The NS option allows learners to record incomplete word knowledge. It was also meant to promote honesty because students would be less likely to over-or underestimate their word knowledge if they weren't forced to pick between YES or NO. To enhance test reliability, students were asked to define the term in either English or Vietnamese if they chose YES. According to [13] Horst (2005), the exam is simple to create, administer, and score. The words in the test were chosen based on the Cambridge A2 Key Vocabulary list.

\subsubsection{Questionnaire}

At the conclusion of the study, participants were given a questionnaire about the MALL program. Some questions were modified from [12] Do (2020), which also seeks to assess participants' views. The researchers utilized both positive and negative items to prevent bias. All products directly answered the study's second research question. The Likert scale was used to easily quantify and evaluate the answers. Respondents were asked to rate the ten items by selecting one of five options: strongly disagree, disagree, neutral, agree, strongly agree. For this reason, students received a multilingual questionnaire in the final week of the study period.

So that the questionnaire would be legitimate and reliable, it was presented to a group of English instructors with a Master's Degree for feedback and modification at TDU and UNETI.

Indicators were measured correctly. The internal consistency of a multi-item questionnaire is evaluated by the Cronbach's alpha coefficient. Between .00 and 1.0 is the typical range. Because the Cronbach's alpha value was above 0.80 , the reliability findings indicated that all questions were designed similarly. 
In short, the questionnaire was valid and reliable. Table 2 shows a Cronbach's alpha of 0.88 .

\subsubsection{Semi-structured interview}

[10] Dahlberg \& McCaig (2010) argue that semistructured interviews allow researchers to get a better understanding of participants' sentiments and emotions regarding a specific subject of interest. The researchers conducted individual interviews in Vietnamese with individuals to better understand their feelings and perspectives. The interview was comprised of open-ended questions designed to corroborate and validate the questionnaire's findings. As a result, poor notes and a lack of rapport between interviewer and interviewee may result from this data collection tool. As a consequence, [34] Seliger \& Shohamy (1989) advise using a tape recorder during interviews for subsequent transcription and analysis. The discussion was radio-recorded and transcribed for analysis, then given to students for review before completing the study.

\section{RESULTS AND FINDINGS}

\subsection{The impacts of MALL on students' vocabulary acquisition}

This section talks about how participants' vocabulary improved between pre-and post-tests. A new procedure using independent t-tests examines test results to measure the importance of word-form and word-meaning improvements. Such tests typically study the evolution of word use as a group across time. Table 2 displays the descriptive statistics of the scores that students achieved on the vocabulary tests.
To evaluate learning improvements, the researchers compared the number of terms that scored YES (I understand the meaning of this word) with the correct meaning on the pre-and immediate post-tests. At the conclusion of the six-week study, all participants scored higher on the 15-word exam than they did at the start. The pre-and post-tests confirmed that the terms scored YES in the pre-test were likewise rated YES in the post-tests. Additionally, almost all YES-marked words with incorrect meaning at the start were likewise marked YES in the post-test with the correct meaning. Students' immediate post-test scores ( $\mathrm{M}=98.57, \mathrm{SD}$ $=16.34)$ are higher than their pre-test scores $(\mathrm{M}=$ $59.46, \mathrm{SD}=5.70$ ), as shown in Table 2. Particularly, there was a 39.11 point increase between the pre-and immediate post-test. The pre-and immediate post-test standard deviations were 5.70 and 16.34, respectively, significantly less than the averages. This implies that participants improved their vocabulary scores by an average of nearly 39 points on the immediate post-test. The averages and standard deviations indicated that the student's vocabulary knowledge had improved.

A paired-sample t-test was used to assess if the difference in means between these two tests is significant at $p<0.05$. The findings indicated that the crucial value of $\mathrm{p}$ was 25 for a two-tailed test with one degree of freedom. The difference in averages between the pre-and immediate post-tests is examined, $\mathrm{t}=-12.70, \mathrm{p}=.000(<0.05)$. The pairedsample t-test findings showed that the difference between pre-and immediate post-test reached a statistically significant level. It demonstrates that students' vocabulary acquisition improves when they utilize mobile-assisted technology in class. In other 
Table 2. Descriptive statistics and paired-sample t-test of pre-test, immediate post-test and delayed post-test

One-Sample Statistics

\begin{tabular}{|l|r|r|r|r|}
\hline & \multicolumn{1}{|c|}{ N } & \multicolumn{1}{c|}{ Mean } & Std. Deviation & \multicolumn{1}{c|}{ Std. Error Mean } \\
\hline Pre-test & 26 & 59.46 & 5.70 & 1.11 \\
\hline Immediate post-test & 26 & 98.57 & 16.34 & 3.20 \\
\hline Delayed post-test & 26 & 89.11 & 12.89 & 2.52 \\
\hline
\end{tabular}

Paired Samples Test

\begin{tabular}{|c|c|c|c|c|c|c|c|c|c|}
\hline & & \multicolumn{5}{|c|}{ Paired Differences } & \multirow[b]{3}{*}{$\mathrm{l}$} & \multirow[b]{3}{*}{ df } & \multirow{3}{*}{$\begin{array}{l}\text { Sig. (2- } \\
\text { tailed) }\end{array}$} \\
\hline & & \multirow[b]{2}{*}{ Mean } & \multirow{2}{*}{$\begin{array}{c}\text { Std. } \\
\text { Deviation }\end{array}$} & \multirow{2}{*}{$\begin{array}{l}\text { Std. Error } \\
\text { Mean }\end{array}$} & \multicolumn{2}{|c|}{$\begin{array}{l}95 \% \text { Confidence } \\
\text { Interval of the } \\
\text { Difference }\end{array}$} & & & \\
\hline & & & & & Lower & Upper & & & \\
\hline Pair 1 & $\begin{array}{l}\text { Pre-test - Immediate } \\
\text { post-test }\end{array}$ & -39.11 & 15.70 & 3.07 & -45.45 & -32.77 & -12.70 & 25 & .000 \\
\hline Pair 2 & $\begin{array}{l}\text { Immediate post-test } \\
\text { - Delayed post-test }\end{array}$ & 9.46 & 6.24 & 1.22 & 6.93 & 11.98 & 7.72 & 25 & .000 \\
\hline
\end{tabular}

words, the MALL initiative seemed to be successful in terms of assisting students in developing their vocabulary.

Table 2 also indicates there was no statistically significant difference between immediate post-test and delayed post-test findings. According to the table, the mean score in the post-test reached 98.57 (out of 150) and significantly decreased to 89.11 in the delayed post-test. It was straightforward to determine that the mean score decreased by just 9.46 points between the immediate and delayed posttests, with a 95 percent confidence range spanning from 6.93 to 11.98 . This indicates that students maintained a high number of vocabulary and kept them for an extended length of time.

Additionally, the paired-sample t-test result indicated that the critical value of $\mathrm{p}$ for a two-tailed test with the degree of freedom was 25 and that there was a statistically significant difference between the immediate and delayed post-test findings with a pvalue of .000 , less than 0.05 .

In summary, the aforementioned results indicated a modest variation in performance between immediate and delayed post-test. In other words, four weeks after therapy, there was a reduction in vocabulary acquisition.

The means of pre-test, immediate and delayed post-test can be illustrated in the chart as follows:

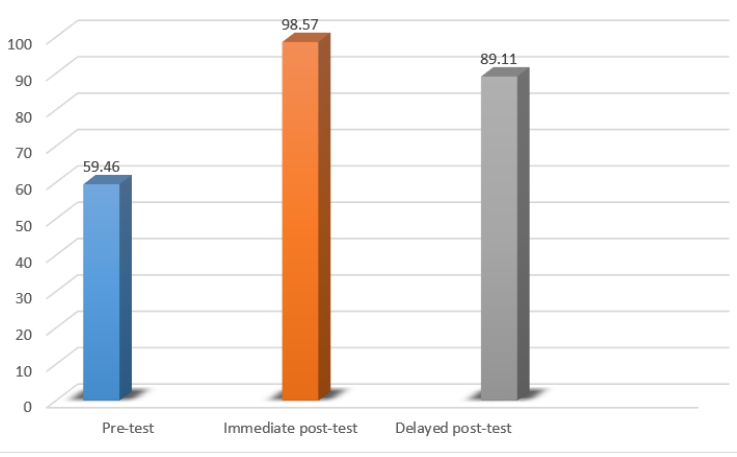

Figure 1: The mean score of pre-test, immediate post-test and delayed post-test

As shown in the above image, the learners' performance in the post-test after the MALL project was, on average, higher than in the pre-test (98.57 in the immediate post-test in comparison with 59.46 in the pre-test). Moreover, the delayed post-test result was somewhat lower than the immediate post-test result, at 89.11 and 98.57, respectively. However, the delayed post-test result was still much greater than the pre-test result. As a result, it can be stated that mobile-mediated technology may assist students in increasing their vocabulary knowledge and that the words acquired while performing technology-assisted activities were maintained without substantial attrition two weeks later.

\subsection{Students' perspectives towards using MALL to learn vocabulary}

For data analysis from the questionnaire, two remarks should be made in relation to the 
findings in Table 3. To begin, the scores for certain negatively phrased questions are inverted to provide the same direction of opinion as to the other positive statements. Second, the mean score for each statement group is computed using the means of the items that comprise the group. Higher scores indicate more optimistic outlooks.
After the study is completed, an overall comparison of students' answers to attitudinal statements is made. The mean scores for each statement and groupings of statements are shown in Table 3 below.

Table 3. Students' perspectives towards using MALL in classrooms

\begin{tabular}{|c|c|c|c|c|}
\hline Categories & Statements & Mean & SD & $\begin{array}{c}\text { Overall } \\
\text { mean }\end{array}$ \\
\hline \multirow[t]{5}{*}{ Cognitive } & $\begin{array}{l}\text { 1. I believe learning with the support of mobile devices in } \\
\text { class is great }\end{array}$ & 4.34 & .56 & \multirow{5}{*}{4.28} \\
\hline & $\begin{array}{l}\text { 5. I believe that mobile devices can promote interaction and } \\
\text { collaboration in class. }\end{array}$ & 4.46 & .51 & \\
\hline & 10. I feel comfortable when mobile devices to learn in class. & 4.50 & .51 & \\
\hline & 3. I believe using mobile devices in class causes distraction & 3.38 & .69 & \\
\hline & $\begin{array}{l}\text { 9. I find it hard to use mobile devices in learning activities in } \\
\text { class. }\end{array}$ & $4.73^{*}$ & .45 & \\
\hline \multirow[t]{3}{*}{ Affective } & 6. I enjoy classroom activities with mobile devices & 4.49 & .47 & \multirow{3}{*}{4.43} \\
\hline & $\begin{array}{l}\text { 2. I do not feel more interested in doing tasks with mobile } \\
\text { devices assigned by the teacher }\end{array}$ & $4.61 *$ & .57 & \\
\hline & $\begin{array}{l}\text { 8. I feel worried about using my mobile devices to complete } \\
\text { assigned tasks in class }\end{array}$ & $4.19 *$ & .84 & \\
\hline \multirow{2}{*}{$\begin{array}{l}\text { Future } \\
\text { Behavior }\end{array}$} & 7. I will join more class activities if I can use mobile devices & 3.96 & .66 & \multirow[t]{2}{*}{4.11} \\
\hline & $\begin{array}{l}\text { 4. I would like to get the teacher's guidance to better use } \\
\text { mobile devices in class. }\end{array}$ & 4.26 & .66 & \\
\hline
\end{tabular}

\section{(*) Items with reversed score}

When mean ratings for individual items are examined in Table 3 , it becomes clear that item 10 got the highest rating, with a mean score of 4.50 . Additionally, SD is a tiny value of 0.51 . This graph demonstrates that the majority of students had a highly positive scale. In other words, they firmly think that MALL intervention increased their vocabulary. As with item 10, item 9 got a very high rating, with a mean score of 4.73 and a standard deviation of 0.45 . It can be concluded that the students liked utilizing mobile devices in-class activities and were happy with their progress in learning English. As shown in Table 3, all items got high ratings, with a mean score ranging from 3.38 to 4.50 and SD values ranging from 0.45 to 0.84 . Furthermore, the mean scores for three aspects of attitude, namely cognitive, emotional, and future behavior, are 4.28, 4.43, and 4.11, respectively. The findings show that students had a positive opinion about MALL as a means of vocabulary acquisition.
MALL usage in the classroom was found to be the most preferred method by participants in semistructured interviews. It was shown that participants' general attitudes about MALL usage for learning were positive, while this was not the case for the previous learning period. Despite this, many respondents expressed reservations regarding the appropriateness of certain uses: the worry of being distracted, difficulty in using, and dread. Additionally, participants suggested many ways to improve MALL's usage in the classroom: "There should be no testing on mobile devices," "The teacher should be able to supervise the class," and "Mobile devices are suitable for group work."

As they responded to the question regarding the challenges associated with MALL use, the majority of respondents said that learning inside the classroom was hampered by a variety of factors. Additionally, participants were asked to justify their answers by considering these points. Firstly, 
participants indicated possible phone activities such as social media use, gaming, and so on, all of which caused a distraction. The second restraint is the lack of wifi connection on the campus. Finally, the participants were forced to rely on their $3 \mathrm{G} / 4 \mathrm{G}$ connections, which they described as often inconsistent and unreliable.

Participants described their learning activities as perplexing since they required them to be completed in class using their phones, which was a new experience for many of them. However, some teachers' instructions were ambiguous, often leaving students puzzled.

Regarding students' overall feelings towards the implementation of MALL inside the classroom, the majority of participants had positive attitudes about MALL usage in schools. Participants' final responses were favorable when they had both positive ideas and feelings regarding MALL. As a consequence, participants expressed positive attitudes about smartphone use in the classroom. Several interviews were performed to get a more accurate picture of students' attitudes about MALL and to validate the findings. The following examples demonstrate how cognitive, emotional, and behavioral perspectives may be expressed.

In terms of cognitive components, students 1,3 and 14 predicted that using mobile phones by teachers to distribute assignments would result in more motivated learners. Besides, students 4, 8, 11, 13, 21 shared a similar view on the merits of MALL in making the learning process more efficient and simpler. Moreover, students 7, 9, 15, 19, 24, 25 commented the amount of information given by MALL is enormous. Rather than buying a large number of books, a mobile phone with an Internet connection may be more cost-effective stuff, especially for EFL learners.

Regarding effective attitude, students 2, 6, 16, 26 responded that they got excited when they played Quizizz, Nearpod and Kahoot! on their phone; students 12,14 and 17 stated they were all overjoyed when they were allowed to use their phones in class to accomplish tasks assigned by the instructors.

Concerning students' behavior, the majority of participants agreed to use mobile devices more to study at school. Even with the above findings, however, the research also found that students had little digital literacy and were prone to distraction. Student 1, 3, 8, 9, 10, 15, 19 and 23 reported that they had never been allowed to utilize this unique teaching method in any of their prior classes, and they were even prohibited from taking their phones to class; no matter what the cause was. Several interviewees said their experience with mobile learning was confusing and unsettling while they were in university, for instance, "Because I have never use those apps before, it is tough for me to use on my cell phone" or "It was comfortable and inconvenient when I got a message while I was performing tasks on my phone".

\section{DISCUSSION}

This study aims to determine whether or not students' vocabulary knowledge increased as a consequence of their use of MALL. Following the session, it is clear that word knowledge increased significantly. This finding is consistent with the students' vocabulary development in [37] Thornton \& Houser (2005), [24] Lu (2008), [43] Yang (2012), [28] Nguyen (2016), [12] Do (2020). When MALL was utilized in class for eight weeks, YES marks were only used on terms that had their definitions in the pre-test. However, in the post-test, students were able to answer YES to a much larger number of words and give correct definitions. Following the session, the authors conducted a follow-up evaluation with students to ascertain their vocabulary objectives. Although vocabulary acquisition decreased somewhat between the immediate and delayed post-test, the results showed an overall increase in that area. Despite this, the percentage rise over the prior test shows that students retained more vocabulary after a two-week break. While the changes were modest, it is possible that students' word memory may deteriorate if they do not practice with MALL for an extended period of time. MALLs, moreover, have some attraction for students. According to the study, all informants own mobile devices. While MALL is less expensive and more easy to use than other computer systems, it also has a higher level of dependability. When utilized appropriately, these devices may be beneficial teaching tools. This result aligns with [12] Do (2020)'s confirmation of the MALL importance when she investigated higher education students' preferences towards mobile device use inside the classroom.

In general, the research found that MALL employment improved students' receptive language comprehension and vocabulary size when the test results indicated a statistically significant improvement. Perhaps it was because the children engaged in learning activities that were either too brief or did not fully use MALL's benefits. In particular, sometimes students found it challenging to learn with MALL due to their varying levels of digital literacy and attentiveness. Furthermore, in the Vietnamese educational context, implementing mobile devices as learning tools for teacher instruction is relatively new. Indeed, some school policies ban students from using mobile phones in the 
classroom. The majority of students enter university with minimal prior understanding of the subject.

According to the researchers, students' views and attitudes about MALL changed significantly during the intervention, particularly in terms of their cognitive, emotional, and future actions. Almost twothirds of students said that MALL increased their participation in-class activities as a consequence of the cognitive component. Students that took part in the MALL research stated that they enjoyed classroom activities, were not tired, and found studying English to be more enjoyable. However, if the children's worries are addressed, their anxieties may subside. Students are worried that their mobile devices will divert their attention away from the lesson. Besides, mobile devices provide a range of leisure options, including social networking, texting, and gaming. As a result, it's simple to see why this worry exists. This problem must be resolved via the use of a plan or instructional method. Additionally, students expressed dissatisfaction with the way in which their teacher gave instructions. When teachers use mobile devices, one of the challenges they face in adapting their teaching approach to incorporate MALL. Both the students and the teachers are unfamiliar with MALL. Teaching children how to use their cell phone for different activities is a problem that may be seen when they give instructions. As a result, a teacher training course should be offered to educate students on how to maximize their learning time. According to [23] Liu and Cain (2016), teachers may have opted not to use mobile devices in their courses due to the difficulties associated with MALL adoption. As a result, teacher training in pedagogy is critical for maximizing the benefits of MALL.

\section{CONCLUSION}

Technological advances have had a profound effect on education, altering almost every aspect of it. While considerable emphasis is placed on technology-mediated teaching and learning, MALL is a sector that has shown benefits and is growing. Particularly, smart phones have grown in popularity. The author decided to perform this action research to examine the impact of MALL on twentysix student vocabulary acquisition and attitudes about MALL after they had an awareness of MALL's critical function in language learning. Pre-test, immediate and delayed post-tests, questionnaires, and interviews were used to elicit information on the usage of MALL. The statistical test indicated a significant difference in pre-and two post-test scores. This shows how MALL aided in the development of students' vocabularies. Additionally, students expressed positive preferences about the utilization of mobile devices in class. MALL was deemed beneficial and easy to use by the majority. Additionally, students developed an enthusiasm for classroom learning with mobile devices. As a result, it's simple to understand why their future behavior in MALL will be positive.

It is evident that more subjects need to be recruited to participate in different locations to be of value to the study. This may assist in generalizing the results. In addition to the current study, a comparison of the perceptions of learners and educators may be conducted. Therefore, MALL attitudes may be better understood and explained. In addition, lessening worries may lead to an even stronger personal stance. If teachers or instructors create teaching methods or schemes to counter distractions, this goal may be met. Additionally, improved Wi-Fi connectivity within the classroom will help boost MALL usage. Surprising as it may seem, instructors should be trained in the art of giving instructions. Clarity and conciseness in teachers' instructions may help cut down on the time it takes to learn. The professors may also arrange a seminar at the beginning of the term to provide students an introduction to MALL in the classroom.

According to the study, a fresh strategy should be taken to teaching and learning English. MALL is beneficial in an academic setting when utilized correctly, since it aids in the language learning process. Language learners who utilize portable devices may enhance their learning potential via the usage of apps. Additionally, the increased usage of mobile devices and student data necessitates the adoption of mobile learning activities. As such, instructors must use caution while implementing MALL. The integration of information technology and sciences, especially MALL, has changed classroom instruction and student autonomy. Even yet, some instructors and students may struggle to adjust. Teachers were considered necessary by students. Due to their lack of access to contemporary technology, their training requirements were much greater. It is recommended that students get a brief introduction to technology at the start of the course.

\section{REFERENCES}

[1] Auzmendi, E., Evaluacióndelas Actitudesha ciala Estad'istica en Estudiantes Universitarios y Factores que las determinan. Universidad de Deusto, Bilbao, 1991.

[2] Auzmendi, E., Las actitudes hacia la matema'tica-estad'istica en las ense nanzas medias y universitarias. Bilbao, Mensajero, 1992.

[3] Benettayeb, A., Extensive reading and 
vocabulary teaching. Revue Academique des Etudes Sociales et Humaines, 3, 2010, pp. 2030.

[4] Brown, R., Extensive reading in the EFL class (Extensive reading in practice colloquium). Paper presented at the JALT International Conference, $3^{\text {rd }}, 2000$.

[5] Cavus, N. \& Ibrahim, D., M-learning: An experiment in using SMS to support learning new English language words. British Journal of Educational Technology, 40(1), 2007, pp. 78-91.

[6] Cherian, E. J., Williams, P., Mobile learning: The beginning of the end of classroom learning. Paper presented at the The World Congress on Engineering and Computer Science WCECS 2008, October 22-24, San Francisco.

[7] Chinnery, G. M., Emerging technologies, going to the MALL: Mobile assisted language learning. Language Learning \& Technology 10(1), 2006, pp. 9-16.

[8] Collins, G. T., English class on the air: Mobile Language Learning with cell phones. In the Fifth IEEE International Conference on Advanced Learning Technologies, 5-8 July 2005 (pp. 402-404). Kaohsiung, Taiwan: IEEE.

[9] Cresswell, J. W, Educational research: Planning, conducting, and evaluating quantitative ( $5^{\text {th }}$ ed.), 2014. Boston: Pearson Education, Inc.

[10] Dahlberg, L. \& McCaig, C., Practical Research and Evaluation: A Start-to-Finish Guide for Practitioners, 2010, London: Sage

[11] Day, R. R, \& Bamford, J., Extensive reading in the second language classroom (6 ed.), 2005, Cambridge: Cambridge University Press.

[12] Do, T. T., Mobile-assisted language learning in a university context in Vietnam: Students' attitudes. VNU Journal of Foreign Studies, 36(1), 2020, pp. 103 - 116.

[13] Horst, M., Learning L2 vocabulary through extensive reading: A measurement study. Canadian Modern language review, 61(3), 2005, pp. 355-382.

[14] ITU, The World in 2009: ICT Facts and
Figures. Report retrieved November 3, 2009 from http://www.itu.int/ITUD/ict/material/Telecom09_flyer.pdf

[15] Joseph, R. P., Incidental acquisition of vocabulary by reading. The reading matrix, 11(2), 2011, pp. 135-139.

[16] Kakihara, D. \& Sorensen, C., Expanding the "mobility" concept. ACM SIGGROUP Bulletin, 22(3), 2001, pp. 33-37.

[17] Kennedy, C. \& Levy, M., L“Italiano al telefonino: Using SMS to support beginners ${ }^{\text {ee }}$ language learning. ReCALL 20(3), 2008, pp. 315-330

[18] Khachai, H., An investigation into extensive reading on EFL students vocabulary acquisition: A case study of third-year LMD students of English at the University of Biskra. (Master of Arts), University of Biskra, Biskra, Algeria, 2016.

[19] Kiernan, P. J. \& Aizawa, K., Cell phones in task-based learning: Are cell phones useful language learning tools? ReCALL 16(1), 2004, pp. 71-84.

[20] Kukulska-Hulme, A., Will mobile learning change language learning? The Journal of the European Association for Computer-Assisted Language Learning, 21(2), 2009, pp. 157-165.

[21] Kweon, S., O., \& Kim, H. R., Beyond raw frequency: Incidental vocabulary acquisition in extensive reading, Reading in a foreign languages, 20(2), 2008, pp. 191-215.

[22] Lewis, M., The lexical approach: The state of ELT and a way forward. Dove, UK: Language Teaching Publications, 1993.

[23] Liu, H., \& Cain, William (Eds.), Investigating mobile-assisted English foreign language learning and teaching in China: Issues, attitudes and perceptions. In Wenhao Tao (Series Ed.), Investigating mobile-assisted English foreign language learning and teaching in China: Issues, attitudes and perceptions, 2016. https://doi.org/10.4018/978$1-5225-0177-0$

[24] Lu, M., Effectiveness of vocabulary learning via mobile phone. Journal of Computer Assisted Learning 24, 2008, pp. 515-525.

[25] Meara, p., Second language acquisition: Lexis. The encyclopedia of language and linguistics. 
Oxford: Pergamon, 7, 1994, pp. 3276-3228.

[26] Nah, K. C., White, P. \& Sussex, R., The potential of using a mobile phone to access the Internet for learning EFL listening skills within a Korean context. ReCALL 20(3), 2008, pp. 331-347.

[27] Nation, I. s. p., Testing and teaching vocabulary. Guidelines, 5(1), 1983, pp. 12- 15.

[28] Nguyen, N. V., Mobile Learning in Language Teaching Context of Vietnam: An Evaluation of Students' Readiness. Ho Chi Minh National University of Education Science Journal, 7(85), 2016, pp. 16-27.

[29] Pettit, J. \& Kukulska-Hulme, A., Going with the grain: Mobile devices in practice. Australasian Journal of Educational Technology 23(1), 2007, pp. 17-33.

[30] Pigada, M. \& Schmitt.N., Vocabulary acquisition from extensive reading: A case study. Reading in a foreign language, 18(1), 2006, pp. 1-28.

[31] Richards, J. c., \& Lockhart, c., Reflective teaching in second language classrooms. USA: Cambridge University Press, 1994.

[32] Samuels, J., Wireless and handheld devices for language learning." Proceedings of the 19th Annual Conference on Distance Teaching and Learning, Madison, WI, 2003. http://www.uwex.edu/disted/conference/Resou rce_library/proceedings/03_50.pdf

[33] Schmitt, N., Vocabulary in language teaching. New York: Cambridge University Press, 2020.

[34] Seliger, H. W \& Shohamy, E., Second Language Research Methods. Oxford: Oxford University Press, 1989.

[35] Soltani, R., Extensive reading: A stimulant to improve vocabulary knowledge. Studies in Literature and Language, 2(3), 2011, pp. 161.

[36] Stockwell, G., Vocabulary on the move: Investigating an intelligent mobile phonebased vocabulary tutor. Computer Assisted Language Learning 20(4), 2007, pp. 365-383.

[37] Thornton, P. \& Houser C., Using mobile phones in English education in Japan. Journal of Computer Assisted Learning 21, 2005, pp. 217-228.

[38] Traxler, J., Defining, discussing, and evaluating 